\title{
Entegre Raporlamanın Firma Karlılı̆̆ına Etkisi: Bankacılık Ve Çimento Sektörü Üzerine Bir Uygulama*
}

\author{
Şerife ÖNDER** \\ İlknur ÇELİK***
}

\section{ÖZET}

Finansal bilgilerin raporlanması ile başlayan kurumsal raporlama süreci, sosyal ve çevresel raporların da eklenmesiyle sürdürülebilirlik raporlaması olarak devam etmiştir. Finansal raporlamanın eksikliklerini gidermek amacılla geliştirilen sürdürülebilirlik raporlamasının zaman içinde bazı eksiklikler içerdiği tespit edilmiş ve bunun çözümü için de son yıllarda entegre raporlama kavramı ortaya çıkmıştır. Entegre raporlama finansal ve finansal olmayan bilgilerin tek bir raporda birleştirmesini içeren, yenilikçi bir raporlama türüdür.

Bu çalışmanın amacl, entegre raporlamanın firma karlılı̆̆ına bir etkisinin bulunup bulunmadığının tespit edilmesidir. Çalışmada entegre rapor hazırlayan ve Borsa İstanbul'da işlem gören bankacılı ve çimento sektöründe yer alan 29 firmanın 2016-2019 yılları arasındaki 116 firmalyıl verisi kullanılmıştır. Panel veri yöntemi ile yapılan analiz sonucunda entegre raporlamanın düşük de olsa firmaların karlılı̆̆ arttıran bir etken olduğu tespit edilmiştir.

Anahtar Kelimeler: Entegre Raporlama, Karlılık, Borsa Istanbul (BIST), Panel Veri Analizi

JEL Sınıflandırması: M40, M41

The Effect Of Integrated Reporting on Firm Profitability: An Implementation on Banking and Cement Sector

\section{ABSTRACT}

The corporate reporting process which started with the reporting of financial information has coninued as sustainability reporting with the addition of social and environmental reports. It has been determined that sustainability reporting, which was developed in order to eliminate the deficiencies of financial reporting, also contained some deficiencies over time and the concept of integrated reporting has emerged in recent years to solve this. Integrated reporting is an innovative type of reporting that combines financial and non-financial information into a single report. The purpose of this study is to determine whether integrated reporting has an effect on firm profitability or not. In the study, the data of 116 firm / year between 2016-2019 of 29 firms that prepare integrated reports and are in the banking and cement sector in Borsa Istanbul, were used. As a result of the analysis made with the Panel Data Method, integrated reporting is a factor that increases the profitability of the firms, even if they are low.

Keywords: Integrated Reporting, Profitability, Istanbul Stock Exchange (BIST), Panel Data Analysis Jel Classification: $M 40$, M41

\footnotetext{
* Makale Gönderim Tarihi: 08.06.2021, Makale Kabul Tarihi: 19.07.2021 , Makale Türü: Nicel Analiz

** Doç.Dr. , Dumlupınar Üniversitesi, Kütahya Sosyal Bilimler Meslek Yüksekokulu, serife.onder@dpu.edu.tr, ORCID: 0000-0001-9251-0283.

*** celikilknur95@gmail.com, ORCID: 0000-0001-9644-1131.
} 


\section{GíRiş}

Entegre raporlama alanında pek çok tanım yapılmaktadır. Fakat bunlardan en çok kullanılanı Uluslararası Entegre Raporlama Konseyi (IIRC) tarafından yapılan tanımlamadır. IIRC'nin yapmış olduğu tanımlamaya göre entegre raporlama, "bir kuruluşun stratejisinin, kurumsal yönetiminin, performansının ve beklentilerinin kuruluşun dış çevresi bağlamında kısa, orta ve uzun vadede değer yaratmayı nasıl sağlayacağının, kısa ve öz bir şekilde bildirilmesi" olarak tanımlanmaktadır (IIRC, 2013:7; Busco vd., 2013:4; Abeysekera, 2013:229). Aktaş ve Kargin (2013)'e göre entegre raporlama, bir firmanın hem finansal hem de finansal olmayan bilgilerini bir araya getirerek bir bilgi grubu ortaya konmasidır. $\mathrm{Bu}$ sebeple, “Tek Rapor” olarak isimlendirilmektedir.

Entegre raporlar, yatırımcıları firmaların stratejisi hakkında daha iyi bilgilendirmektedir. Entegre raporlama, finansal olmayan bilgi ve verilere odaklanarak çevresel, sosyal, yönetimsel ve finansal etmenlerle ilgili uzun vadeli yatırımlar için bir motivasyon oluşturmaktadır. Entegre raporlamayı kullanan firmalar hem tedarik zincirlerindeki çalışanlarının hem de çalışanlarının çalışma koşullarına, fabrikaların ve diğer tesislerin bulunduğu topluluklarla olan ilişkilere ve tazminat yapısına ilişkin bilgileri sağlayarak, markalarının ve itibarlarının değerini artırmaktadırlar (Pavlopoulos vd., 2019:15).

Entegre raporlar yatırımcıların yanında müşteriler, tedarikçiler ve bankalar gibi diğer bilgi kullanıcılarına da veri sağlamaktadır (Eccles vd., 2019:16). Asıl hedef, firmalar için kar artırımı ve uzun vadeli kurumsal başarı hakkında alternatif bir düşünme şekline yol göstermektir.

Entegre raporlamanın temelini oluşturan entegre düşünce iki bileşenden oluşmaktadır. $\mathrm{Bu}$ bileşenlerden ilki, bir firmanın stratejisi, yönetimi, geçmiş performansı ve gelecekteki beklentilerinin birbiri ile bağlantısının oluşturulmasıdır. İkincisi ise, firmaların departmanlarının birbiri ile bağlantısının sağlanmasıdır. Bir firma entegre rapor oluşturma sürecinde, firma içerisindeki bağlantıların daha iyi kavranması için firma içerisindeki birimlerin birbirleriyle olan ilişkilerini araştırmalıdır (WICI, 2013:1).

Firmalar entegre rapor hazırlayarak uzun vadeli vizyonunu ve stratejisini, içinde bulunduğu durumunun yanında kaynaklarını ve değerlerini bilgi kullanıcılarına iletmektedir. Bunların yanında, geleceğe dönük hedeflediği metotları ve takip edeceği yolu da paylaşmaktadır. Diğer raporlamalardan farklı olarak entegre raporlama sadece firmanın geçmişine yönelik bilgiler sunmakla kalmaz aynı zamanda geleceğine de odaklanmaktadır. Bu sayede diğer raporlardan ayrılmaktadır (Ercan ve Kestane,2017:75). 2011:83);

Entegre raporlamanın firmalara sağladıkları faydalar şunlardır (Eccles ve Serafeim,

- $\quad$ Finansal ve finansal olmayan performans arasındaki bağlantının daha iyi anlaşılmasını sağlamaktadır,

- Güvenilir ve zamanında hazırlanan finansal olmayan bilgiler üretmek için iç ölçüm ve kontrol sistemleri geliştirilmesini gerektirmektedir,

- $\quad$ İşletmenin itibar riskini düşük seviyede tutmasına katkı sağlamaktadır,

- Çalışanların firmaya olan bağlılıklarını artırmaktadır, 


\author{
- Müşterileri sürdürülebilirlik konularına önem veren kararlı müşteriler \\ olmaktadir, \\ - Sağlanan bilgiler 1şı̆̆ında uzun vadeli yatırımcıların dikkatini çekmek \\ konusunda katkı sağlamaktadır.
}

\title{
2. TÜRKIYY'DE ENTEGRE RAPORLAMA
}

Entegre rapor hazırlayan firmalar açısından ülkeler değerlendirildiğinde en çok entegre raporun Güney Afrika Cumhuriyeti’nde yer alan firmalar tarafından hazırlandığı görülmektedir. Yine Hollanda, Brezilya ve Avustralya'da da entegre raporun firmalar tarafından diğer ülkelere göre daha çok yayınlandığı görülmektedir. Bunun en önemli nedeni, ülkelerin entegre raporlamayı hükümet, borsalar veya yapılan düzenlemeler ile teşvik etmesidir (Önder, 2018:79). Türkiye'de ise entegre raporlama ile ilgili herhangi bir yasal düzenleme ya da teşvik söz konusu olmamakla birlikte firmalar tamamen kendi inisiyatifleri ile entegre rapor hazırlamaktadır (Yüksel, 2018: 486).

Entegre rapor ile ilgili ilk çalışmalar Türkiye'de 2011 yılında başlamış ve ilk entegre rapor 2015 yılında yayınlanmıştır. 2020 yılı itibariyle 2019 yılına ait entegre rapor yayınlayan özel firma sayısı 10 adet, sivil toplum kuruluşu 2 adet, kamu kurumu 4 adet, yerel yönetim 1 adet ve düzenleyici ve denetleyici kurum olan Borsa İstanbul 1 adet olmak üzere toplam 18 kurum bulunmaktadır. Entegre rapor yayınlayan kurum ve kuruluşların sayısının her geçen yıl arttığ1 görülmektedir. Buna göre ülkede 2015 yılında sivil toplum kuruluşu tarafından yayınlanan tek bir entegre rapor bulunurken 2016 yılında bu sayı 5'e, 2017 yılında 7'ye, 2018 yılında 12'ye ve 2019 yılında ise 18 entegre rapor yayınlanmıştır (entegreraporlamatr.org, 2020).

\section{LITERATÜR TARAMASI}

Bowen (1953), "Social Responsibilities of the Businessman" kitabında, firmaların iç sınırlarının haricinde dış paydaşlarının da bulunduğunu belirtmiştir. Fakat Friedman firmaların temel sorumluluğunun kâr üzerine olduğunu, toplumun talepleri altında ezilmemesi gerektiğini belirtmektedir (Bhasa, 2015:117). Firmaların toplumun taleplerini karşılamasının kârlılığı üzerinde bir etkisi olabilir mi? Bu soru literatürde sıkça araştırılmaktadır. Brown vd. (2004) kurumsal yönetim ve firma performansı arasında pozitif ilişki olduğunu ileri sürmüştür. Bu ilişki Bhatt ve Bhatt (2017) tarafından Malezya üzerine yaptıkları çalışma ile, Coleman (2008) Afrika üzerine yaptığı çalışma ile, Barbu ve Bocean (2007) Romanya üzerine yaptıkları çalışma ile de benzer şekilde ifade edilmiştir. Gaeremynck vd. (2010) ise Avrupa ülkeleri üzerine yaptıkları çalışmada bu ilişkiyi doğrulamışlardır. Mashayekhi ve Bazaz (2008) İran, Zhaoyang ve Udaya (2012) Vietnam üzerine yaptıkları çalışmalarda ise tam zıt sonuçlar ortaya koymuşlardır. Sharma ve Arora (2016) Hindistan üzerine yaptıkları çalışmada, herhangi bir ilişki bulunmadığını tespit etmişlerdir. Fallatah ve Dickins (2012) Sudi Arabistan üzerine yaptıkları çalışmada da yine bir ilişki ortaya koyamamışlardır.

Benzer bir tartışma kurumsal sürdürülebilirlik ve firma performansı üzerinde yaşanmaktadır. Kurumsal sürdürülebilirliğin firma performansına olumlu yansıdığını belirten çalışmalar olduğu gibi aksini iddia eden çalışmalar da bulunmaktadır. Örneğin Tomšič vd. (2015) Slovenya üzerine yaptıkları çalışmada kurumsal sürdürülebilirliğin firma performansına olumlu yansıdığını ileri sürmektedirler. Japonya, Güney Kore, Endonezya ve 
Hindistan üzerine Laskar ve Gopal (2018) yaptıkları çalışmada benzer sonuçları vurgulamaktadır. Ngatia (2014) Kenya, Jalila ve Komathy (2019) Malezya üzerine yaptıkları çalışmalarda aynı sonuca ulaşmışlardır. Garg (2015) Hindistan üzerine yaptıkları çalışmada kurumsal sürdürülebilirlik raporlamasının uzun vadede firma performansına olumlu katkısına rağmen kısa vadede firma performansını olumsuz etkilediğini ileri sürmüştür. Laskar (2019) Güney Kore ve Hindistan üzerine yaptığı çalışmada, kurumsal sürdürülebilirliğin Güney Kore'de firma kârlılığını olumlu yönde etkilerken Hindistan'da olumsuz etkilediğini vurgulamaktadır. Lopez vd. (2007) Dow Jones Endeksi üzerine yaptığı çalışma ile Ho ve Taylo (2007) ise Japonya ve ABD firmaları üzerine yaptıkları çalışma ile kurumsal sürdürülebilirlik ve firma performansı arasında ters yönlü ilişki olduğunu raporlamışlardır.

Kurumsal raporlamanın en üst aşaması olan entegre raporlama ile ilgili son y1llarda firma performansına olan etkisi inceleme konusu yapılmaktadır. Ching vd. (2017) Brezilya üzerine yaptıkları çalışmada kurumsal sürdürülebilirlik raporlaması ile firma performansı arasında bir ilişki olmadığını ileri sürmüşlerdir. 2016 yılında Lee ve Yeo, Güney Afrika'daki firmalarda entegre raporlama kullanılmasından sonraki süreçte, entegre raporlama açıklamalarındaki kesitsel varyasyon ile firma performansı arasındaki ilişkiyi araştırmışlardır. Çalışmanın sonucunda, firma değerlemesiyle entegre raporlama arasında olumlu bir ilişki olduğu sonucuna ulaşmışlardır. Ayrıca entegre raporlamanın, maddi olmayan varlıkları fazla olan ve birden fazla iş segmenti bulunan firmalar gibi organizasyonel karmaşıklığı yüksek olan firmalarda, bilgi ortamını iyileştirdiğini öne sürmüşlerdir.

Entegre raporlama firma performansı arasındaki ilişkinin yanında farklı açılardan da entegre raporlamanın etkilerini inceleyen çalışmalar mevcuttur. 2017 yılında Zhou vd., Güney Afrika borsasında işlem gören firmalar üzerine yaptıkları çalışmalarında, firmaların entegre raporlamayla uyumu arttıkça, analistlerin tahmin doğruluğunun arttığını ve sermaye maliyetinin azaldığını tespit etmişlerdir. Bernardi ve Stark (2018), rapor kullanıcılarının entegre raporlamanın faydalarına dair algılarını değerlendirmek amacıyla bir çalışma yapmışlardır. 2008-2012 yıllarını örneklem olarak alan çalışmada, Güney Afrika'da entegre raporlama ile firmanın sosyal ve yönetimsel performansının gelecekteki mali performansıyla ilişkilendirmenin, hissedarlara firma ve geleceğine ait daha iyi anlayış sağladığı sonucuna ulaşmışlardır.

\section{ENTEGRE RAPORLAMANIN FIRMA KÂRLILIĞINA ETKISINIIN ANALIZ EDILMESI}

Bu çalışma BİST bankacılık ve çimento sektöründe işlem gören firmaların kârlılığına, entegre raporlamanın etkisinin bulunup bulunmadığını test etmeyi amaçlamıştır. Örneklem olarak bu sektörlerin seçilmesinin nedeni, söz konusu sektörlerde entegre raporlamanın diğer sektörlere göre daha yoğun olmasından kaynaklanmaktadır. Türkiye'de entegre rapor hazırlayan kurumların listesi Entegre Raporlama Türkiye A $\breve{g}$ (ERTA) web sayfası olan entegreraporlamatr.org adresinde düzenli olarak yayınlanmaktadır.

BİST bankacılık ve çimento sektöründe işlem gören 29 firmaya ait 2016-2019 yıllarına ait 116 firma/yıl verisi örneklem olarak alınmıştır. 2016 yılının örneklem olarak seçilmesinin nedeni Türkiye’de özel sektörde yer alan firmaların 2016 y1lından itibaren entegre rapor hazırlamaya başlamış olmalarıdır. Örneklemde yer alan firmaların internet sitelerinde ve Kamuyu Aydınlatma Platformunda açıklamış oldukları yıllık finansal tabloları, 
faaliyet raporları ve entegre faaliyet raporları kullanılarak firmalara ilişkin değişkenler elde edilmiştir.

BİST bankacılık sektöründe işlem gören 14 firmadan 3'ü (Garanti BBVA, Türkiye İş Bankası, Türkiye Sınai Kalkınma Bankası) entegre rapor hazırlamaktadır. Yine BİST çimento sektöründe işlem gören 15 firmadan 4'ü (Adana Çimento, Aslan Çimento, Çimsa, Nuh Çimento) entegre rapor hazırlamaktadır. Entegre rapor hazırlayan firma sayısı 2019 yılı sonunda toplam 7 firma olmuştur. Örneklem olarak bu iki sektörde yer alan firmaların tamamı alınmıştır. Bu iki sektörde yer alan 29 firmanın 7'si entegre rapor hazırlamakta, 22 firma ise entegre rapor hazırlamamaktadır. Yine firmaların kârlılığı da çalışmada temel alınan literatüre uygun olarak, Aktif Kârlılık Oranı (Return On Assets ROA) ile ölçülmüştür. Samy (2019) tarafından yapılan çalışmada kullanılan modelden faydalanılarak oluşturulan ölçüm modeli Eşitlik 1'de gösterilmektedir. Eşitlik 1'de gösterilen doğrusal model, SPSS 15 ve Eviews 9.1 programları vasıtasıyla analiz edilmiştir. Analiz yöntemi olarak dengeli panel veri analizi kullanılmıştır. Dengeli panel veri analiz yönteminin seçilmesinin nedeni, varsayım ve yöntem testlerinden bazılarının dengesiz panel veri analizinde çalışmamasıdır.

$$
\operatorname{Roa}_{i t}=\beta_{0}+\beta_{1} \text { EntRap }_{i t}+\beta_{2} \text { Buyukluk }_{i t}+u_{i t}
$$

Eşitlik 1'de yer alan model ile aktif kârlılık oranı üzerinde entegre raporlamanın etkisi analiz edilecektir. Eşitlik 1'deki modelde yer alan değişkenler ve açıklamaları aşağıda verilmektedir.

Roa: Firmanın varlıklarının yönetim verimliliğini göstermektedir. Dolayısı ile bu değer firma karlılığının pozitif bir ölçüsüdür (Chen ve Chen, 2011.122). Bu nedenle ROA modelin bağımlı değişkeni olarak kullanılmıştır. i’nci firmanın, t zamanındaki aktif kârlılık oranını göstermektedir. Değişkenin hesaplanması için gerekli olan veriler, firmaların faaliyet raporlarından alınmıştır.

EntRap: i'nci firmanın, t zamanında entegre raporlama yapıp yapmadığını gösteren değişkendir. Söz konusu değişken firmaların 2016-2019 yıllarının incelenmesi sonucunda entegre raporlamaya sahip olması durumunda 1 olmaması durumunda sıfır değeri verilerek oluşturulmuştur.

Buyukluk: i’nci firmanın, t zamanındaki büyüklügüüü temsil etmek üzere satışlarının doğal logaritması alınarak modelde kullanılmıştır. Değişkenin hesaplanması için gerekli olan veriler, firmaların faaliyet raporlarından alınmıştır.

\section{BULGULAR}

Eşitlik 1'deki modelde yer alan bağımlı değişken olan Roa ve bağımsız değişkenler olan EntRap ve Buyukluk değişkenlerinin tanımlayıcı istatistikleri ve normallik testine ilişkin sonuçları Tablo 1'de gösterilmektedir. 
Tablo 1. Tanımlayıcı İstatistikler

\begin{tabular}{lcrrr}
\hline Değişkenler & Ortalama & Standart Hata & En Büyük & En Küçük \\
\hline \hline Roa & 0.045569 & 0.063131 & 0.302353 & -0.144956 \\
\hline EntRap & 0.206897 & 0.406838 & 1.000000 & 0.000000 \\
\hline Buyukluk & 21.22324 & 1.849955 & 24.56766 & 17.92354 \\
\hline
\end{tabular}

Tablo 1'de yer alan değerlere göre örneklem olarak alınan 29 firmanın 2016-2019 yıllarındaki ortalama aktif kârlılık oranı 0,045569'dur. Bu rakamın en düşük olduğu firmada almış olduğu değer -0,144956 iken, en yüksek değere ulaştığı firmada almış olduğu değer 0,302353'tür. İşletmelerin entegre raporlama yapıp yapmadığını gösteren EntRap değişkeninin ortalama değeri 0,206897'dir. Bu oran örneklem içerisinde yer alan firmaların söz konusu örneklem dönemi içerisinde ortalama olarak yaklaşık \%21'lik bir entegre raporlamaya sahip olduğunu ifade etmektedir. Buyukluk değişkeninin ortalama değeri 21,22324'tür. Bu değişkenin en yüksek olduğu firmada değer 24,56766'ya ulaştığı, en düşük olan firmada ise 17,92354'e düştüğü Tablo 1'den görülebilmektedir.

Panel veri analizlerinde değişen varyans, yatay kesit bağımlılığı ve otokorelasyon problemlerinin olmadığı varsayılmaktadır. Bu sorunları göz ardı ederek tahminler yapmak standart hataları bozacağı için etkinliğe engel olacaktır. Dolayısı ile söz konusu sorunların varlıkları kontrol edilmeli ve bu sorunlar tespit edildiğinde uygun yöntemler ile panel veri analizi gerçekleştirilmelidir (Tatoğlu, 2018.209-211). Eşitlik 1'de yer alan modelde otokorelasyon probleminin olup olmadığını sınamak için Wooldridge Otokorelasyon Testi, değişen varyans problemi olup olmadığını sınamak içinde Greene Değişen Varyans Testi yapılmıştır (Önder ve Kaya, 2019:20). Bu testler ile elde edilen sonuçlar Tablo 2'de raporlanmıştır. Eşitlik 1'de yer alan modelin kesit boyutunun zaman boyutundan büyük olması nedeniyle yatay kesit bağımlılığ sonuçları yine Tablo 2'de raporlanmıştır.

Tablo 2. Varsayımların Test Edilmesi

\begin{tabular}{llcc}
\hline \multicolumn{1}{c}{ Hipotez } & \multicolumn{1}{c}{ Test Adı } & Test İstatistiği & Olasılık Değeri \\
\hline \hline$H_{0:}$ Otokorelasyon Yok & Wooldridge & 0.179 & 0.179 \\
\hline$H_{1:}$ Otokorelasyon Var & Otokor. Testi & & \\
\hline$H_{0:}$ Sabit Varyans & Greene Değişen & 43.740 & 0,0001 \\
\hline$H_{1:}$ Değişen Varyans & Varyans Testi & & \\
\hline$H_{0:}$ Kesit Bağımlılık Yok & Pesaran's Kesit & \multirow{2}{*}{8.410} & 0,0001 \\
\hline$H_{1:}$ Kesit Bağımlılık Var & Bağımlılık Testi & & \\
\hline
\end{tabular}

Tablo 2'de otokorelasyon problemi olup olmadığını sınamak için yapılan Wooldridge Otokorelasyon Testinin olasılık değerinin 0,179 olduğu görülmektedir. Bu değer \%10 istatistiki önem düzeyinin bile üstünde olmasından dolayı örneklemde otokorelasyon probleminin olmadığını göstermektedir. Değişen varyans problemini test etmek için kullanılan Greene Değişen Varyans Testi ile yatay kesit bağımlılı̆̆ını test etmek için 
kullanılan Pesaran Kesit Bağımlılık testlerinin olasılık değerleri ise \%1 istatistiki önem düzeyinde bir anlamlılığ göstermektedir. Dolayısı ile örneklemde değişen varyans ve kesit bağımlılık problemi söz konusudur. Örneklemde kesit boyutunun zaman boyutundan büyük olduğu da dikkate alınarak yatay kesit bağımlılığına ve değişen varyans problemlerine dirençli tahminciler üretebilen Driscool - Kraay tahmincisi kullanılarak Eşitlik 1'deki model analiz edilecektir.

Tablo 3. Analiz Modelinin Seçimi

\begin{tabular}{lllc}
\hline Hipotez & Test Adı & Test İstatistiği & Olasılık Değeri \\
\hline$H_{0:} E\left(\varepsilon_{i, t} / x_{i t}\right)=0$ & Hausman Testi & 1.826694 & 0.4012 \\
\hline$H_{0:} E\left(\varepsilon_{i, t} / x_{i t}\right)<>0$ & & & \\
\hline
\end{tabular}

Panel veri analizinde gözlemlenemeyen birim etkiler söz konusu olabilmektedir. Eğer etkilere hata terimi gibi rassal bir değişken olarak davranılıyor ise rassal etkiler, her bir yatay kesit gözlem için tahmin edilen bir değer olarak davranılıyor ise sabit etkiler söz konusu olabilmektedir (Tatoğlu, 2018:79). Eşitlik 1'de yer alan modelde rassal etkiler ve sabit etkilerden hangisinin geçerli olduğunu test edebilmek için Hausman Testi gerçekleştirilecektir (Önder ve Gündüz, 2019:30). Hausman testinin sonuçları Tablo 3 'te raporlanmıştır. Tablo 3’te Hausman Testinin olasılık değerinin 0,4012 olduğu görülmektedir. Söz konusu değer $\% 10$ istatistiki önem düzeyinde bile istatistiki açıdan anlamlı bulunmamıştır. Bu nedenle Eşitlik 1'de yer alan modelde rassal etkilerin geçerli olduğu kabul edilmiştir.

Tablo 4. Analiz Bulguları

\begin{tabular}{clll}
\hline \multicolumn{1}{c}{ Değişkenler } & Katsayı & Standart Hata & Olasılık Değeri \\
\hline \hline EntRap & 0,0216 & 0,0086 & $0,087^{* *}$ \\
\hline Buyukluk & $-0,0074$ & 0,0081 & 0,429 \\
\hline C & 0,1994 & 0,1982 & 0,388 \\
\hline Kesit G. 29 & $\mathrm{R}^{2}$ & & Wald Ki-Kare: 13,72 \\
Göz. Say. 116 & 0,1029 & Prob 0.0010* \\
\hline
\end{tabular}

*\%1, ve **\%10 istatistiki önem düzeyinde anlamlıdır.

Tablo 2 ve Tablo 3'te yer alan bulgular sonucunda Eşitlik 1'de yer alan modelin analizi için Driscool - Kraay tahmincisi ve rassal etkiler yöntemi kullanılacaktır. Elde edilen sonuçlar Tablo 4 'te raporlanmıştır. Tablo 4 'te yer alan sonuçlara göre modelin genel olarak $\% 1$ istatistiki önem düzeyinde anlamlı olduğu ve $\mathrm{R}^{2}$ değerinin $\% 10$ düzeyinde olduğu görülmektedir. Modelde yer alan EntRap ve Buyukluk değişkenlerinden sadece EntRap değişkeni istatistiksel olarak anlamlı bulunmuştur. EntRap değişkeninin olasılık değeri 0,087'dir. Bu değer söz konusu değişkenin \%10 istatistiki önem düzeyinde anlamlı olduğunu göstermektedir. EntRap değişkeninin Roa değişkeni üzerindeki etkisini gösteren katsayısı 0,0216'dır. Dolayısı ile EntRap değişkeninde meydana gelebilecek bir birimlik değişim, Roa değişkeni üzerinde aynı yönde 0,0216 birimlik bir etki yaratabilecektir. Bu sonuç entegre raporlamanın düşükde olsa firma karlılığını arttıran bir etken olduğunu ortaya koymaktadır. 


\section{SONUÇ}

Firmalar, çevreleri ile bilgi akışını yayınladıkları raporlar ile gerçekleştirmektedir. Yayınlanan bu raporlar uluslararası alandaki yenilikler ile birlikte önemli ölçüde değişim geçirmiştir. Kurumsal raporlamanın geldiği son süreçte hazırlanan entegre raporlar, firmaların paydaşları ile bilgi akışını düzenleyen önemli bir araç konumuna gelmiştir. Firmalar entegre rapor ile paydaşlarına sadece finansal değil sosyal ve çevresel anlamda düzenli ve güvenilir bir bilgi akışı gerçekleştirmektedir. Gerçekleşen bu bilgi akışı acaba firmaların esas amacı olan kârlılığına bir etkisi olmakta mıdır sorusu literatürde oldukça sık araştırılan konuların başında gelmektedir. Kurumsal yönetim raporlaması ve kurumsal sürdürülebilirlik raporlamasının firma kârlılığına etkisini inceleyen literatürde oldukça fazla çalışma bulunmaktadır. Fakat entegre raporlama olgusu yeni başlayan bir süreç olması nedeni ile bu alandaki çalışmalar oldukça az sayıdadır. Bu çalışma literatürdeki söz konusu eksikliği Türkiye özelinde doldurmayı amaçlamaktadır.

Türkiye'de 2015 yılında ilk olarak başlayan entegre raporlama olgusu firmaların olduğu kadar belediyeler ve sivil toplum kuruluşlarının da ilgisini çekmektedir. Henüz oldukça sınırlı sayıda BİST firması entegre raporlama faaliyetini gerçekleştirmektedir. Bu firmalarında özellikle banka ve çimento sektöründe yer alan firmalar olması sebebiyle çalışmada bu iki sektörde yer alan firmalar incelenmiştir. Bu sektörlerdeki entegre raporlamanın firma kârlılığına olan etkisi 2016-2019 yıllarına ilişkin 116 firma/yıl verisi ile analiz edilmiştir. Entegre rapor hazırlayan firmalar, Entegre Raporlama Türkiye Ağı (ERTA) web sayfası olan entegreraporlamatr.org adresinden tespit edilmiştir. Samy (2019) tarafından yapılan çalışmadaki modelin veri alınarak kurgulanan bu çalışmada, entegre raporlamanın firma karlılığına düşük de olsa pozitif yönde etkisinin bulunduğu sonucuna ulaşılmıştır. Entegre raporlama ve firma karlılığı ile ilgili literatürde henüz çok fazla çalışma bulunmamakla birlikte bulunan sonucun Lee ve Yeo'nun yaptığı çalışma ile uyumlu olduğu tespit edilmiştir.

Dengeli panel veri yöntemi ile gerçekleştirilen analiz sonucunda ortaya konan bu pozitif ilişsinin nedenini, bilgi açıklama seviyesinin kalitesi ve yüksekliği ile açıklamak mümkündür. Açıklanan bilgi ne kadar yüksek olursa yatırımcıların ve alacaklıların firmalara olan güveninin de o kadar yüksek olması ve bunun sonucunda firmaların kârlılığının da yüksek olması beklenmektedir. Entegre raporlama yatırımcılar ve alacaklılar başta olmak üzere tüm paydaşlara, ihtiyacı olan finansal ve finansal olmayan bilgileri sistematik bir şekilde sağlayabilmektedir. Çalışmanın sonuçları Türkiye'de entegre raporlamanın gelişmesinin desteklenmesi gerektiğini göstermektedir. Ayrıca söz konusu bu çalışma, entegre raporlamanın diğer sektörlerde yer alan firmalar için yapılacak çalışmalara da bir temel teşkil etmesi beklenmektedir.

\section{KAYNAKLAR}

Abeysekera, Indra (2013), "A Template for Integrated Reporting", Journal of Intellectual Capital, 14 (2), pp. 227-245.

Arora, Akshita - Sharma, Chandan (2016), "Corporate Governance and Firm Performance in Developing Countries: Evidence From India”, Corporate Governance.16(2), pp. 420436. 
Barbu Catalin M. - Bocean Claudiu G. (2007), "Corporate Governance and Firm Performance”, Management \& Marketing - Craiova, 7(1), pp. 125-131.

Bernardi, Cristiana - Stark, Andrew. W. (2018), "Environmental, Social and Governance Disclosure, Integrated Reporting, and The Accuracy of Analyst Forecasts”, The British Accounting Review, 50(1), pp. 16-31.

Bhasa Malla Praveen (2015), “Mapping The Growth And Direction of Corporate Governance Research: A Broad Overview of Literature Between 1930-2014" Journal of Governance and Regulation , 4(1), pp. 1-112.

Bhatt, Padmanabha Ramachandra - Bhatt, R. Rathish (2017), "Corporate Governance and Firm Performance in Malaysia", Corporate Governance, 17 (5), pp. 896-912.

Brown, Lawrence D. - Caylor, Marcus L. (2004), “Corporate Governance and Firm Performance" (December 7, 2004). SSRN: https://ssrn.com/abstract=586423 or http://dx.doi.org/10.2139/ssrn.586423

Busco, Cristiano - Frigo, L. Mark - Quattrone, Paolo - Riccaboni, Angelo (2013), “Towards Integrated Reporting: Concepts, Elements and Principles", İçerisinde Integrated Reporting (pp. 3-18) , Ed. Busco, Cristiano - Frigo, L. Mark - Quattrone, Paolo Riccaboni, Angelo, Springer, Cham.

Chen, Li Ju - Chen, Shun Yu (2011), “The Influence of Profitability on Firm Value With Capital Structure as The Mediator and Firm Size and Industry as Moderators”, Investment Management and Financial Innovations, 8(3), pp. 121-129.

Ching, Hong Yuh - Gerab, Fábio - Toste, Thiago Henrique (2017), “The Quality of Sustainability Reports and Corporate Financial Performance: Evidence From Brazilian Listed Companies”, SAGE Open, 7(2), pp.1-9.

Coleman Kyereboah Anthony (2008), “Corporate Governance and Firm Performance in Africa: a Dynamic Panel Data Analysis”, Studies in Economics and Econometrics, 32(2), pp. 1-24.

Eccles, G. Robert - Krzus, P. Michae - Solano, Carlos (2019), “A Comparative Analysis of Integrated Reporting in Ten Countries”. Available at SSRN 3345590.

Eccles, G. Robert - Serafeim, George (2011), “Accelerating The Adoption of Integrated Reporting”, İçinde CSR Index, (pp. 70-92) Ed. Francesco de Leo ve Matthias Vollbracht, InnoVatio Publishing Ltd.

Entegre Raporlama Türkiye, Entegreraporlama.org.tr (Erişim Tarihi:03.03.2020).

Ercan, Cuma - Kestane, Ali (2017), “Entegre Raporlama ve Türkiye’deki Uygulama Örnekleri Üzerine Bir Araştırma”, Kırklareli Üniversitesi İktisadi ve İdari Bilimler Fakültesi Dergisi, 6(4), ss. 73-86. 
Fallatah, Yaser - Dickins Denise (2012), "Corporate Governance and Firm Performance and Value in Saudi Arabia”, African Journal of Business Management, 6, pp. 1002510034.

Gaeremynck, Ann - Sercu, Piet M. F. A. - Renders, Annelies, (2010), “Corporate-Governance Ratings and Company Performance: A Cross-European Study", Corporate Governance: An International Review, 18(2), pp. 87-106.

Garg, Priyanka (2015), “Impact of Sustainability Reporting on Firm Performance of Companies in India", International Journal of Marketing and Business Communication, 4(3), pp. 38-45.

Ho, Jennifer Li-Chin - Taylor, Martin E. (2007), “An Empirical Analysis of Triple BottomLine Reporting and its Determinants: Evidence From The United States and Japan”, Journal of International Financial Management \& Accounting, 18(2), pp. 123-150.

IIRC (International Integrated Reporting Council) (2013), “International Integrated Reporting Framework”, International Integrated Reporting Council, London.

Jalila Johari - Komathy (2019), “Sustainability Reporting and Firm Performance: Evidence in Malaysia”, International Journal of Accounting, Finance and Business (IJAFB), 4(17), pp. 1-7.

Laskar, Najul - Gopal Maji, Santi (2018), "Disclosure of Corporate Sustainability Performance and Firm Performance in Asia", Asian Review of Accounting, 26(4), pp. 414-443.

Laskar, Najul (2019), “Does Sustainability Reporting Enhance Firms Profitability? A Study on Select Companies from India and South Korea”, Indian Journal of Corporate Governance, 12(1), pp. 2-20.

Lee, Kin-Wai - Yeo Gillian Hian-Heng (2016), “The Association Between Integrated Reporting and Firm Valuation”, Review of Quantitative Finance and Accounting, 47(4), pp. 1221-1250.

Lopez, M. Victoria - Garcia, Arminda - Rodriguez, Lazaro (2007), "Sustainable Development and Corporate Performance: A Study Based on The Dow Jones Sustainability Index”, Journal of Business Ethics, 75(3), pp. 285-300.

Mashayekhi, Bita - Bazaz, Mohammad S. (2008). Corporate Governance and Firm Performance in Iran. Journal of Contemporary Accounting \& Economics, 4(2), pp. 156-172.

Ngatia, Charles N. (2014), "Exploring Sustainability Reporting for Financial Performance of Selected Companies Listed at the Nairobi Securities Exchange in Kenya", International Academic Journal of Economics and Finance, 1(4), pp. 32-48. 
Önder, Hüseyin - Gündüz, İbrahim (2019), Nükleer Enerji Tüketiminin Makroekonomik Belirleyicileri: Seçilmiş Oecd Ülkeleri Üzerine Panel Veri Analizi, Öneri Dergisi, 14(51), ss, 18-37.

Önder, Hüseyin - Kaya, Orhan Can (2019), “Elektrikli Araçların Satışı Üzerinde SosyoEkonomik Faktörlerin Etkisi: Bir Panel Veri Analizi”, Anemon Muş Alparslan Üniversitesi Sosyal Bilimler Dergisi, 7(1), ss. 17-21

Önder, Şerife (2018), Kurumsal Raporlamanın Yeni Trendi Entegre Raporlama, 1. Bask1, Ekin Yayınevi, Bursa

Pavlopoulos, Athanasios - Magnis, Chris - Iatridis, George Emmanuel (2019), “Integrated Reporting: An Accounting Disclosure Tool for High Quality Financial Reporting”, Research in International Business and Finance, 49, pp. 13-40.

Samy, Mohamed (2019), “The Impact of Integrated Reporting on Firm Value and Performance: Evidence from Egypt”, Journal of Accounting Research, 3(2), pp. 1-33.

Tatoğlu, Ferda Yerdelen (2018). "Panel Veri Ekonometrisi Stata Uygulamalı", Beta Yayınları, İstanbul.

Tomšič Nastja - Bojnec Štefan - Simčič Blaž (2015), “Corporate Sustainability and Economic Performance in Small and Medium Sized Enterprises”, Journal of Cleaner Production, 108, pp. 603-612.

WICI - The World's Business Reporting Network (2013), “Connectivity: Background Paper for <IR>”, International Integrated Reporting Council, World Intellectual Capital Initiative, London.

Yüksel, F. 2018, "Entegre Raporlama, Değer Yaratma Ve Entelektüel Katma Değer Katsayısı: BİST Kurumsal Yönetim Endeksinde Bir Uygulama”, Muhasebe Bilim Dünyası Dergisi,Özel Sayı; 20, 473-492.

Zhaoyang Guo - Udaya Kga Kumara (2012), "Corporate Governance and Firm Performance of Listed Firms in Sri Lanka”, Procedia - Social and Behavioral Sciences, 40, pp. 664667.

Zhou, Shan - Simnett, Roger - Green, Wendy (2017), “Does Integrated Reporting Matter to The Capital Market?”, Abacus, 53(1), pp. 94-132. 
